\title{
CORRESPONDENCE
}

\section{Climate policy: role of scientists in public advocacy}

In his review of my book Science as a Contact Sport - a personal retrospective account of the development of climate science and policy covering 40 years Roger Pielke Jr misrepresents my position on advocacy (Nature 464, 352-353; 2010).

Pielke fairly represents my decades-old argument that scientists should avoid policy prescriptions. But he omits my frequently stated context: policy advocacy by scientists is inappropriate in formal assessments, such as those of the Intergovernmental Panel on Climate Change or of the US National Academy of Sciences.

As citizens, scientists may have personal-value positions on policy. But when involved in public advocacy, they must clearly lay out their world views and separate the more objective scientific issue of risk assessment from the valueladen risk-management part. Contrary to Pielke's implication, I am aware of this 'paradox'.

Understanding science does not in itself lead to effective policy. In fact, my book demonstrates that special interest or ideological chicanery is more responsible than scientific ignorance for blocking policy. However, as Pielke notes, I did say that if people better understood what is at stake, they'd be likely to make better risk-management decisions. Stephen H. Schneider Department of Biology, Woods Institute for the Environment, Stanford, California 94305, USA

e-mail: shs@stanford.edu

\section{Climate policy: dissent over moral as well as factual issues}

In his Review of books by James Hansen and Stephen Schneider (Nature 464, 352-353; 2010),

Roger Pielke Jr misguidedly implies that it is undemocratic for climate scientists to call for action against climate change in the name of science.

The normative assumptions underlying climate-change policy recommendations receive much less public attention than the scientific facts that fuel policy deliberation. The debate proceeds as though there is a common moral sense that we can rely on when arguing about climatepolicy issues. Consequently, it seems as if disagreement over policy conclusions can stem only from disagreement about scientific facts. This leads to an absurd situation in which people with no understanding of the scientific arguments feel compelled to challenge the science.

It might be helpful to pay more attention to the normative issues underlying the climate discourse, for example by identifying the disagreement about the relevance of suffering in distant places or times, or the role of uncertainty in normative assessments.

Gregor Betz Universität Stuttgart, Institut für Philosophie, 70174 Stuttgart, Germany e-mail:gregor.betz@philo.unistuttgart.de

\section{What users really want to know from university ratings}

The improvements you describe in university rating systems are welcome (Nature 464, 7-8 and $16-17 ; 2010)$, but they are not notably geared to the interests of the students. We need broader ratings that clearly indicate the practical advantages of studying at a particular university.

Research output is one measure of what a student has gained from higher education. But most science undergraduates see university enrolment primarily as an economic benefit rather than as a path to research. Job satisfaction and choice of profession both affect postgraduation economics, so they should be taken into account. Assessments of education debts and post-graduation employment rates would be useful too.

If such helpful titbits of economic data could be combined with research output, institutional peer assessment, teaching quality, assessment by employers and other factors, ranking schemes would contribute more meaningfully to higher education.

Jimmy J. Zhuang Department of Molecular and Cellular Biology, Harvard University, Cambridge, Massachusetts 02138, USA e-mail:jzhuang@fas.harvard.edu Annie X. Wang Goodwin Procter, Boston, Massachusetts 02109, USA Joyce Y. Zhang Federal Reserve Bank of New York, New York, NY 10038, USA

\section{African students value the results of studying in China}

Your News story describing offers of research collaboration by China to Africa (Nature 464, 477; 2010) conveys an overall negative impression of what I believe to be a successful initiative.

For example, you raise doubts about the calibre of students from Africa who train as scientists in China. But the stiff competition for places would suggest otherwise. Figures from Kenya's ministry of higher education show that China and Germany are the most popular study destinations. My own research, supported by Hong Kong's Research Grants Council, also indicates that China's universities are highly regarded by Kenyan candidates.

African students are not expected to take language courses while studying science in Chinese, as you imply. China's Scholarship Council allows them to study Mandarin intensively for a whole year before they embark on their science coursework, when they can continue to study it part-time.

Your story does not mention successful programmes such as the popular scientific collaboration scheme between
China and South Africa that has been running for more than ten years. There are other longterm examples of collaboration with Ethiopia, Kenya, Egypt and Cameroon.

A comment attributed to me questions how much good the thousands of short-term training courses in China can achieve. But I should point out that the many people I have interviewed after their return from China are positive about their experience on both short-and long-term courses.

Kenneth King Centre of African Studies, University of Edinburgh, Edinburgh EH8 9LD, UK e-mail: kenneth.king@ed.ac.uk

\section{Actions speak louder than words to prevent language extinctions}

Every two weeks a language becomes extinct, according to the United Nations Permanent Forum on Indigenous Issues (see http:// go.nature.com/RLfdzx). The Ethnologue linguistic resource lists 6,912 languages, $75 \%$ of which are spoken by a few indigenous peoples spread over more than 70 countries.

The United Nation's 1996 Declaration of Linguistic Rights calls for linguists, governments and intergovernmental agencies to come up with policies to arrest this trend. In Nepal, for example, 70 indigenous languages are recognized; many of these have been represented in the media for more than a decade. Yet at least 11 have died out, 19 are almost extinct and 23 are endangered.

More effort, increased funding, greater commitment and effective policies are all needed to preserve language diversity, particularly in developing countries.

\section{Yoshina Gautam, Aashish Jha}

Department of Human Genetics, University of Chicago, Illinois 60637, USA e-mail:nepaliaashish@uchicago.edu

Contributions may be submitted tocorrespondence@nature.com. 